\title{
Effects of sixteen week of resistance exercises on some selected cognitive variables development in adolescents with intellectual disabilities
}

\author{
Kefelegn Zenebe ${ }^{1}, \odot$ Kesatie Legesse $^{2}, \odot$ Soumitra Mondal $^{2}, \odot$ Mahmud Abdulkader $^{3}$, \\ Kidanie Aragaw ${ }^{4}$
}

${ }^{1}$ Department of Sport Science, Wollo University, Dessie, Ethiopia.

${ }^{2}$ Department of Sport Science, Mekelle University, Mekelle, Ethiopia.

${ }^{3}$ Institute of Medical Microbiology and Immunology, Mekelle University, Mekelle, Ethiopia.

${ }^{4}$ Department of Statistics, Wollo University, Dessie, Ethiopia.

\begin{abstract}
Intellectual disabilities a serious problem in the entire world and its prevalence is high in school-age children. These difficulties can influence cognitive, social and emotional areas of functioning and has led their families to suffer in economic and social disadvantages than those without disabilities. The main objective of this study was to investigate the effect of sixteen week resistance exercise on cognition developments of school children with intellectual disabilities in Desse \& Kombolcha, Amhara region, Ethiopia. In this Pre-test and post-test study design eighteen adolescents with intellectual disabilities were participated in the study. Paired t-test was fitted to analyze the pre-test and post-test data of the study participants. In order to measure cognitive variables digit span backward, digit span forward, vocabulary and similarity test batteries were used to measure working memory, short term memory, vocabulary knowledge and comparative reasoning respectively before and after sixteen week of the training intervention. After sixteen week of intervention, a significant mean score change was observed in working memory, short term memory, vocabulary knowledge and comparative reasoning respectively $(\mathrm{p}<0.05)$ after training when compared with before training. We concluded that resistance exercise can improve the cognitive skills of adolescents with intellectual disabilities.
\end{abstract}

Keywords. Cognition developments, intellectual disabilities, resistance exercise.

\section{Introduction}

Intellectual disabilities (ID) a serious problem in the entire world (World Health Organization, 1996) and caused by Down's syndrome, fetal alcohol syndrome, central nervous system malignancy (Campbell et al., 2003) and characterized by having motor difficulties and limitations expressed in the performance of sports skills (World Health Organization, 2011) influencing cognitive, social or emotional areas of functioning therefore, to whatever extent a special physical activity and adapted to be able to move forward and towards independent living (Bechara \& Grosub, 2016). These difficulties can influence cognitive, social and emotional areas of functioning and has led their families to suffer in economic and social disadvantages than those without disabilities (Emerson et al., 2010) and discrimination, access to justice and education are the challenges of ID in Africa (Njenga, 2009).

The health benefits of exercise are well studied but the cognition variables improvement benefits of physical exercise are emerging and again needs further study (Pastula et al., 2012). Physical exercise also reported to be beneficial for youth individuals with intellectual disabilities and needs study with 
greater scientific rigor including larger sample sizes, control groups and physical exercise should be recommended based on the area of disability type (Johnson, 2009).

Despite some gaps in the current knowledge, there is enough evidence to support the physical exercise as an intervention to generally prevent cognitive impairment (Porto, 2018). However, exercises with high intensity can result poor in cognition improvements (Smith et al., 2016).The impact of physical exercise on cognition performance development depends on the frequency duration, intensity and type of an exercise (Oertel-Knöchel et al., 2014).

Thus, the physical exercise level of children and adolescents both in the intellectual standards and with intellectual disabilities still remain unsatisfactory (Bryl et al., 2013) and needs further investigations to address the effects of physical exercise on cognition development in terms of design of exercise, training regimens, dose response relationships such as intensity, frequency, types and time of intervention (Chang et al., 2012; Bherer et al., 2013).

To increase the success of a physical activity program for persons with intellectual disabilities, a number of factors such as instructional strategies, activity modification, and motivational strategies such as verbal praise or providing tangible rewards are necessary in order to improve the physical fitness qualities (Frey et al., 2008). Based on this an effective exercise therapy at moderate level may speed up the integration of individuals with intellectual disabilities into society while also significantly lowering their health care costs (Pastula et al., 2012) and can improve the cognition function of children cognition (Lees \& Hopkins, 2013; Fernandes et al., 2018).

The socio economic condition ID in Ethiopia in terms of social life, education, occupation, and economic level is generally poor (Ayele, 2016) and parents face emotional, social economic and material challenges while raising their children with ID
(Weldeab \& Opdal, 2007). Considering the factors affecting the attainments of the goals of a country in relation to create productive human power, the most important approach might be identifying, the parts of a society that needs special treatment in order to develop their productivity at large. Therefore, we identified school children with intellectual disabilities that require more attention in social and economic advantages are to be optimized and lead independent way of life.

To the knowledge of the researcher, no research has been done specifically on the effect of resistance cognitive development among individuals with intellectual disability in Ethiopian. Therefore, we deeply saw the importance of this study participants and their contribution to the development of their countries at large and the lack of studies in this and other related topics in Ethiopia, conducting a study by giving an appropriate volume of exercise intervention can take a step in the field of fast development and improvement of cognitive performance of individuals with ID. Therefore, we motivated to address some selected cognition variables such as verbal knowledge, comparative reasoning, working memory and short term memory in school children with ID using resistance exercise intervention in Desse \& Kombolcha, Amhara region, Ethiopia.

\section{Methods}

\section{Study Setting and Ethical Approval}

Ethical approval was obtained from Mekelle University College of Health Sciences; Health Research Ethics Review Committee (HRERC) with Ref. ERC 1078/2017 dated 26/06/2017 in accordance with Helsinki declaration. A written consent from study participants and assent from their families/guardians was obtained which stated confidentiality and requirements for this study. The study was conducted in Dessie and Kombolch north eastern Ethiopia. 


\section{Study Design and Participants}

Pre-test post-test study design on the effects of resistance exercise intervention adolescents with intellectual disabilities in Dessie-Kombolcha was employed. The participants of this study were free from epilepsy and autism disorders. The whole numbers of these participants were eighteen and placed purposively in to resistance exercise intervention group. After explanation of the purposes of the study and the privacy of information for the participants and their parents/guardians were completely satisfied to cooperate in the participation of the study. When inviting the participants to participate in the process of orientation about how to conduct resistance exercise intervention before the beginning of the main exercise protocol, the parents/guardians of the study participants committed that these study participants can participate in the sixteen week resistance exercise intervention process of this study.

\section{Procedure}

In order to measure cognitive variables digit span backward, digit span forward, vocabulary and similarity test batteries were used to measure working memory, short term memory, vocabulary knowledge and comparative reasoning respectively before and after sixteen week of the training intervention..

The training program consisted of sixteen week of progressive intensity of resistance exercises intervention and conducted after receiving the parental consent. These exercises were performed three sessions a week and each session took forty five minutes. These are ten minutes of warm-up exercises, fifteen to thirty minutes of main resistance workout and five minutes cool-down exercises.

\section{Data Analysis}

Data were entered to an excel spread sheet and cleaned. Statistical analysis was performed using Statistical Package for Social Science (SPSS) version 20. Test results were computed using mean, mean difference and standard deviation. In this study paired t- test was used to compare the pre-test and post-test data of the group on the effects sixteen week resistance exercise intervention on cognition variables in children with intellectual disabilities. The significance level was considered at $\mathrm{P} \leq 0.05$.

\section{Results}

In this study 18 students with intellectual disabilities were studied. Table 2 shows the mean and standard deviation of age, height and mass of the students with ID. The age, height and mass of the students with ID treated with resistance exercise intervention are age $(M=14.25 ; S D=1.136)$, height in meter $(M=$ 1. $51 ; \mathrm{SD}=0.038)$ and mass in kilogram $(\mathrm{M}=49.24$; $\mathrm{SD}=5.89)$.

\section{Table 2}

Demographic characteristic of adolescents with intellectual disabilities.

\begin{tabular}{lc}
\hline Variables & Mean \pm SD \\
\hline Age (year) & $14.25 \pm 1.136$ \\
Height $(\mathrm{m})$ & $1.51 \pm 0.038$ \\
Mass $(\mathrm{kg})$ & $49.24 \pm 5.89$ \\
\hline
\end{tabular}

\section{Table 1}

Training protocol.

\begin{tabular}{lccccl}
\hline Training phases & Weeks & Frequency & Repetition & Time $(\mathrm{min})$ & Exercises \\
\hline Phase- 1 & $1-4$ & 3 & $3-5$ & $15-18$ & Back bridge, Wall seat, Heel raise, Triceps press, \\
Phase-2 & $5-8$ & 3 & $5-8$ & $19-22$ & Overhead, Arm press, Leg press in doorway, Trunk lift, \\
Phase -3 & $9-12$ & 3 & $9-12$ & $23-26$ & Bent knee push up, Side leg rises, Reverse curl, Wall \\
Phase -4 & $13-16$ & 3 & $13-16$ & $27-30$ & \\
\hline
\end{tabular}




\section{Table 3}

The paired t-test analysis on the effect of resistance exercise on cognitive variables.

\begin{tabular}{|c|c|c|c|c|c|}
\hline Variables & Tests & Mean \pm SD & $\mathrm{t}$ & $\mathrm{df}$ & $\mathrm{p}$ \\
\hline \multirow[t]{2}{*}{ Working Memory } & Pre-test & $2.166 \pm 0.707$ & -4.267 & 17 & $0.001^{*}$ \\
\hline & Post-test & $2.778 \pm 0.878$ & & & \\
\hline \multirow[t]{2}{*}{ Short Term Memory } & Pre-test & $3.44 \pm 0.856$ & 3.344 & 17 & $0.004^{*}$ \\
\hline & Post-test & $4 \pm 1.215$ & & & \\
\hline \multirow[t]{2}{*}{ Vocabulary Knowledge } & Pre-test & $14.3889 \pm 3.146$ & 2.322 & 17 & $0.033^{*}$ \\
\hline & Post-test & $15.1111 \pm 3.7399$ & & & \\
\hline \multirow[t]{2}{*}{ Comparative Reasoning } & Pre-test & $6.611 \pm 2.033$ & 2.749 & 17 & $0.014^{*}$ \\
\hline & Post-test & $7.278 \pm 1.903$ & & & \\
\hline
\end{tabular}

$T 3=$ triiodothyronine, $T 4=$ Tetraiodothyronine, $T S H=$ thyroid stimulating hormone, $D F=$ degree of freedom, $M=$ mean and $S D=$ standard deviation.

*The mean difference is significant at $(p<0.05)$.

Table 3 was shown the mean score results at $(\mathrm{p}<$ $0.05)$ between the pre-test and post- test in Working memory $(p=0.001)$, Short term memory $(p=0.004)$, Comparative reasoning $(p=0.014)$ and Vocabulary knowledge $(p=0.033)$.

\section{Discussion}

The objective of this study was aimed to investigate the impact of resistance exercise on vocabulary knowledge; comparative reasoning, working memory and short term memory of school children with intellectual disabilities. The finding revealed that 16 week of resistance exercise intervention had shown statistically a significant mean score difference at $(p<0.05)$ in vocabulary knowledge ( $p$ $=0.033)$, comparative reasoning $(p=0.014)$, working memory $(\mathrm{p}=0.001)$ and short term memory $(\mathrm{p}=$ 0.004 ) treated with resistance exercise following the intervention when compared with before intervention.

The results in this portion of the study are in line with the previous studies (Peig-Chiello et al., 1998; Lachman et al., 2006; Cassilhas et al., 2007; Busse et al., 2008; Bherer et al., 2013) reported that resistance exercise has shown improvement in children cognition. Thus, resistance exercise showed improvements in short term memory and working memory performance (Busse et al., 2008); total memory (Lachman et al., 2006); comparative reasoning and memory (Cassilhas et al., 2007); information processing speed, attention and memory (Chang et al., 2012).

Doing progressive resistant training 2-3 times a week can improve physical and function limitation (Liu \& Latham, 2009). Resistance exercise program designed two to three times per week one to three sets of six to fifteen repetitions with combination of upper and lower body exercise are recommended for youngsters (Swain et al., 2014). Resistant exercise intervention designs in load 60-80\%-1RM with twice per week for six months can positively affect information processing speed, attention memory function and specific types of executive function (Chang et al., 2012). It can prevent and protects from brain damage through increased uptake of circulating IGF-1 by the brain (Carro et al., 2001). These cognitive development benefits might be influenced by many biological mechanisms insulin like growth factor (IGF-1) induced by resistanceexercise training and this hormone is very important to the production of brain derived neural factor (Chang et al., 2012) and prevent the loss of brain tissue (Cotman \& Berchtold, 2002). Although, brain derived neuron trophic factor plays a great role in the developments of central nervous system and 
plasticity of the brain (Autry \& Monteggia, 2012) and regulates synapse function in the central nervous system (Numakawa et al., 2014).

\section{Conclusion}

Resistance exercise can improve cognitive variables such as working memory, short term memory, comparative reasoning and vocabulary knowledge in adolescents with intellectual disabilities.

\section{Acknowledgment}

The authors would like to acknowledge students and their parents, trainer coaches who helped us in this study are greatly appreciated.

\section{Funding}

No external funding was received for this study.

\section{Declaration of Interest}

The authors report no conflict of interest.

\section{References}

Autry, A.E., \& Monteggia, L.M. (2012). Brain-derived neurotrophic factor and neuropsychiatric disorders. Pharmacological Reviews, 64(2), 238-258. doi: doi.org/10.1124/pr.111.005108.

Ayele, T. (2016). The Prevalence and Socio-Economic Condition of Persons with Disabilities in Hosanna Town. Doctoral dissertation, Addis Ababa University, Ethiopia.

Bechara, I., \& Grosub, E.F. (2016). Physical activity and intellectual disabilities. The European Proceedings of Social and Behavioural Sciences, 18, 225-234. doi:10.15405/epsbs.2016.12.30

Bherer, L., Erickson, K. I., \& Liu-Ambrose, T. (2013). A review of the effects of physical activity and exercise on cognitive and brain functions in older adults. Journal of Aging Research, 2013. doi.org/10.1155/2013/657508.

Bryl, W.,Matuszak, K., \& Hoffman, K. (2013). Physical activity of children and adolescents with intellectual disabilities-a public health problem. Hygeia Public Health, 48(1), 1-5.

Busse, A.L., Jacob Filho, W., Magaldi, R., Coelho, V., Melo, A.C., \& Betoni, R.A. (2008). Effects of resistance training exercise on cognitive performance in elderly individuals with memory impairment: results of a controlled trial. Einstein, 6(4), 402-407.

Campbell, J.M., Morgan, S.B., \& Jackson, J.N. (2003). Autism spectrum disorders and mental retardation. Brown, R.T. (Ed.). In: Handbook of pediatric psychology in school settings. London: Lawrence Erlbaum Associates Publishers.

Carro, E., Trejo, J. L., Busiguina, S., \& Torres-Aleman, I. (2001). Circulating insulin-like growth factor I mediates the protective effects of physical exercise against brain insults of different etiology and anatomy. Journal of Neuroscience, 21(15), 5678-5684. doi.org/10.1523/JNEUROSCI.21-15-05678.2001

Cassilhas, R.C., Viana, V.A., Grassmann, V., Santos, R.T., Santos, R.F., Tufik, S., \& Mello, M.T. (2007). The impact of resistance exercise on the cognitive function of the elderly. Medicine and Science in Sports and Exercise, 39(8), 1401-1407. doi: 10.1249/mss.0b013e318060111f.

Chang, Y.K., Pan, C.Y., Chen, F.T., Tsai, C.L., \& Huang, C.C. (2012). Effect of resistance-exercise training on cognitive function in healthy older adults: a review. Journal of Aging and Physical Activity, 20(4), 497517. doi.org/10.1123/japa.20.4.497.

Cotman, C.W., \& Berchtold, N.C. (2002). Exercise: a behavioral intervention to enhance brain health and plasticity. Trends in Neurosciences, 25(6), 295-301.

Emerson, E., Shahtahmasebi, S., Lancaster, G., \& Berridge, D. (2010). Poverty transitions among families supporting a child with intellectual disability. Journal of Intellectual and Developmental Disability, 35(4), 224-234.

Fernandes, R.M., Correa, M.G., Dos Santos, M.A.R., Almeida, A.P.C.P.S.C., Fagundes, N.C.F., Maia, L.C., Lima, R.R. (2018). The Effects of Moderate Physical Exercise on Adult Cognition: A Systematic Review. Frontiers in Physiology, 9, 667. doi.org/10.3389/fphys.2018.00667

Frey, G.C., Stanish, H.I., \& Temple, V.A. (2008). Physical activity of youth with intellectual disability: review 
and research agenda. Adapted Physical Activity Quarterly, 25(2), 95-117.

Johnson, C.C. (2009). The benefits of physical activity for youth with developmental disabilities: a systematic review. American Journal of Health Promotion, 23(3), 157167. doi.org/10.4278/ajhp.070930103.

Lachman, M. E., Neupert, S. D., Bertrand, R., \&Jette, A. M. (2006). The effects of strength training on memory in older adults. Journal of Aging and Physical Activity, 14(1), 59-73. doi: doi.org/10.1123/japa.14.1.59I.

Lees, C., \& Hopkins, J. (2013). Effects of aerobic exercises on cognition, academic achievement and psychological function in children: A systematic review of Randomized control trials. Prev Chronic Dis, 10 (E174); doi: http://dx.doi.org/10.5888/pcd10.130010.

Liu, C.J., \& Latham, N.K. (2009). Progressive resistance strength training for improving physical function in older adults. Cochrane Database of Systematic Reviews, (3). CD002759. doi:10.1002/14651858.CD002759.pub2

Njenga, F. (2009). Perspectives of intellectual disability in Africa: epidemiology and policy services for children and adults. Current Opinion in Psychiatry, 22(5), 457461.

Numakawa, T., Richards, M., Nakajima, S., Adachi, N., Furuta, M., Odaka, H., \& Kunugi, H. (2014). The role of brain-derived neurotrophic factor in comorbid depression: possible linkage with steroid hormones, cytokines, and nutrition. Frontiers in Psychiatry, 5, 136.

Oertel-Knöchel, V., Mehler, P., Thiel, C., Steinbrecher, K., Malchow, B., Tesky, V., \& Schmitt, A. (2014). Effects of aerobic exercise on cognitive performance and individual psychopathology in depressive and schizophrenia patients. European Archives of Psychiatry and Clinical Neuroscience, 264(7), 589-604. doi: 10.1007/s00406-014-0485-9.
Pastula, R. M., Stopka, C. B., Delisle, A. T., \& Hass, C. J. (2012). Effect of moderate-intensity exercise training on the cognitive function of young adults with intellectual disabilities. J Strength Cond Res, 26(12), 3441-3448. doi: 10.1519/JSC.0b013e318270fc83.

Peig-Chiello, P., Perrig, W.J., Ehrsam, R., Staehelin, H.B., \& Krings, F. (1998). The effects of resistance training on well-being and memory in elderly volunteers. Age and Ageing, 27(4), 469-475. doi.org/10.1093/ageing/27.4.469.

Porto, F.H.G., Coutinho, A.M., de Souza Duran, F.L., de Sá Pinto, A.L., Gualano, B., Buchpiguel, C.A., Busatto, G., Nitrini, R., \& Brucki, S.M.D. (2018). Aerobic training modulates salience network and default mode network metabolism in subjects with mild cognitive impairment. NeuroImage: Clinical, 19, 616-624. https://doi.org/10.1016/j.nicl.2018.05.002 .

Smith, M., Tallis, J., Miller, A., Clarke, N. D., GuimarãesFerreira, L., \& Duncan, M. J. (2016). The effect of exercise intensity on cognitive performance during short duration treadmill running. Journal of Human Kinetics, 51(1), 27-35. doi: 10.1515/hukin-2015-0167

Swain, D.P., Brawner, C.A., \& American College of Sports Medicine. (2014). ACSM's resource manual for guidelines for exercise testing and prescription. Philadelphia: Wolters Kluwer Health/Lippincott Williams \& Wilkins.

Weldeab, C.T., \& Opdal, L.R. (2007). Raising a child with intellectual disabilities in Ethiopia: what do parents say? https://files.eric.ed.gov/fulltext/ED496076.pdf

World Health Organization. (1996). Mental retardation division of health and prevention of substance abuse. International Classification of Diseases. 10th Edition. ICD10. Geneva.

World Health Organization. (2011). World report on disability 2011. https://www.who.int/disabilities/ world_report/2011/report.pdf. 